\title{
Temporal Stability and Transferability of Non-Motorized and Total Trip Generation Models
}

\author{
Judith L. Mwakalonge ${ }^{1 *}$, Juhann C. Waller ${ }^{2}$, Judy A. Perkins ${ }^{3}$ \\ ${ }^{1}$ Department of Civil and Mechanical Engineering and Technology, South Carolina State University, \\ Orangeburg, USA \\ ${ }^{2}$ Department of Civil and Environmental Engineering, North Carolina A \& T State University, \\ Greensboro, USA \\ ${ }^{3}$ Department of Civil and Environmental Engineering, Prairie View A \& M University, Prairie View, USA \\ Email: jmwakalo@scsu.edu, juhann.waller@covington-waller.com, juperkins@pvamu.edu
}

Received June 23, 2012; revised July 21, 2012; accepted August 17, 2012

\begin{abstract}
Transportation systems provide a means for moving people and the goods from which they are spatially separated. Of the two means of surface transportation, the motorized mode is used extensively for utilitarian travel in developed countries. The increasing reliance on motorized travel has contributed to increased traffic congestion, air pollution, and greenhouse emissions. Non-motorized travel has recently received significant attention as a means to reduce congestion and environmental problems and improve human health. However, non-motorized modeling is generally underdeveloped. This study investigated some changes in non-motorized and total travel and the characteristics of the traveling public in 1990, 1995, 2001, and 2009 using a national travel survey. The study also investigated the temporal transferability of linear-regression trip generation models for non-motorized and total travel under such changes. High-income households made fewer non-motorized trips in 1990 and 1995 compared to 2001 and 2009. Persons aged 50 and over showed an increased demand for non-motorized travel, whereas children aged 0 - 15 showed a decreasing preference for non-motorized travel over time. Regarding temporal stability, only the coefficient for single-adult households with no children was stable across all of the analysis years. For both non-motorized and total travel, most model parameter estimates were stable short term but not long term. In general, the total travel models transferred better than non-motorized models, both short term and long term. Despite not finding universal stability in model parameter estimates, the models were marginally able to replicate travel in 2009 relative to the locally estimated 2009 model.
\end{abstract}

Keywords: Non-Motorized; Transferability; Temporal; Total Travel

\section{Introduction}

Transportation systems provide a means for moving people and the goods from which they are spatially separated. There are two means of transportation: motorized and non-motorized. The motorized segment is mostly comprised of passenger and freight vehicles that are used extensively for utilitarian travel in developed countries. The non-motorized travel segment is mostly comprised of bicycling and walking, which are not typically used extensively as means for utilitarian travel in developed countries. In the US, the use of motorized vehicles as a means of transportation has been dominant for years and has been associated with the sprawling land use patterns in most US cities as well as the relatively low cost of operating motorized vehicles and nominal parking costs $[1,2]$. The increasing reliance on motorized means of transportation has contributed to increased traffic con-

${ }^{*}$ Corresponding author. gestion, air pollution, and greenhouse emissions. The Urban Transportation Report Card [3] reports that transportation is responsible for 20 to 60 percent of the carbon emissions in major US cities. Additionally, the Urban Mobility Report [4] shows that the peak congested hours increased from 4.5 hours per day in 1982 to 7.1 hours per day in 2002. The travel time index, which is defined as the ratio of travel time in rush hour to the travel time during the free-flow period increased from 1.09 in 1982 to 1.24 in 2007 , and wasted fuel per peak traveler increased by 15 gallons during the same period [5]. Furthermore, the report indicates that in 2002, 58 percent of all major road systems were congested, compared to only 34 percent in 1982. The World Health Organization (WHO) at the European Region (1999) also reported that autogenerated pollution is responsible for more deaths than all traffic accidents. Consequently, more agencies are seeking or implementing strategies to reduce reliance on motorized travel. 
Non-motorized travel has recently received significant attention as a means to reduce congestion and environmental problems and improve human health. Transportation policymakers view increased non-motorized travel as a solution to traffic congestion caused by motorized travel, and politicians view non-motorized travel as an indicator of community livability. With increased obesity and related diseases, the public health community views increased non-motorized travel as an indicator of greater physical activity, which can be used to explain community health levels (Clifton et al. 2004). These reasons and others have motivated research in non-motorized travel. In an effort to reduce air pollution resulting from transportation, the Federal Government enforced the Clean Air Act Amendments (CAAA) of 1990, which require Metropolitan Planning Organizations (MPOs) to demonstrate conformity with the National Ambient Air Quality Standards (NAAQS) in their transportation development and investment plans. As a result, several agencies and communities have considered encouraging non-motorized travel as one of the solutions to mitigate community problems associated with traffic congestion, air quality, and human health. For example, the San Francisco Bicycle Coalition is working to transform the city's streets and neighborhoods into more livable and safe places for promoting bicycle transportation [3].

To promote usage of non-motorized travel, transportation planners and policymakers need to assess the current usage and identify the benefits of implementing and improving non-motorized facilities compared to other alternatives. Further, transportation policymakers require a thorough understanding of non-motorized travel behavior to adequately estimate the impact of policy actions. However, the literature related to the evaluation of bicycle and pedestrian infrastructure and programs on travel behavior and emissions is generally underdeveloped [6,7]. Additionally, studies [2,8] indicate the need to collect accurate data to better understand the behavioral aspects of non-motorized travel and develop quantitative nonmotorized models.

Most studies $[2,9,10]$ have modeled non-motorized travel using a single cross-sectional dataset. A study by Edmond et al. [9] investigated the gender differences in bicycling behavior using single cross-sectional data collected via an online survey in 2006. Bhat et al. [2] studied non-motorized travel behavior in the San Francisco Bay Area using a single cross section of data collected in 2000. The use of cross-sectional data for demand modeling requires the assumption that surveyed households or individuals are at the demand-supply equilibrium point at the time of the survey, and that the travel behavior relationship established at this equilibrium point remains stable over time. Forecasting travel with such models means that variations in travel behavior observed across units (households or individuals) in the cross section can be extrapolated over time to predict the travel behavior of households to account for changes in their demographic composition. This assumption has been suggested to be too strong, and empirical studies indicate that travel behavior of households of similar composition does not necessarily remain stable over time.

A wide range of research on trip generation models with respect to stability and transferability has been conducted, mostly on motorized travel. Kannel and Heathington [11] studied the transferability of two trip frequency models estimated on 1964 cross-sectional data to predict travel in 1971 in Indianapolis, Indiana (US). Cotrus et al. [12] studied the transferability of linear-regression and Tobit trip generation models estimated on 1986 cross-sectional data to 1997 in Israel. The former study found a shift in auto ownership for selected households, but overall the models predicted total travel sufficiently from one period to another in the same region. The latter study did not find sufficient temporal transferability, which was due to differences in economic conditions that existed in the two periods. Furthermore, literature points out that travel demand is affected by the state of the economy and the price of oil [13]. For example, studies in the 1970s [14] indicated that people changed their travel habits in response to the energy crises that occurred during that decade. In addition, most studies have investigated temporal transferability using only two crosssectional datasets. Such studies, though beneficial, may fall short on accounting for the effects of programs implemented in multiple years. A thorough understanding of the effect of temporal economy, demographic, and land use changes over multiple years is im- portant in modeling non-motorized travel. Such information would help planners and policymakers adequately estimate the impact of promoting non-motorized travel in reducing vehicular emissions and traffic congestion. Existence of temporal stability would help agencies employ the different strategies with less regard to temporal changes. Further, an investigation on temporal transferability of non-motorized travel demand models would advance the understanding of the influence of changes in the urban structure on non-motorized travel demand, as compared to total travel demand. Thus, this study had the following objectives:

- Investigate the change in the relationship between non-motorized travel, the characteristics of the traveling public, and the surrounding environment.

- Empirically assess the temporal transferability of non-motorized trip generation models over multiple years.

- Comparatively analyze the temporal stability of nonmotorized and total trip generation models.

The remainder of this paper is organized as follows: 
First is a discussion of the data used in this study, followed by a descriptive analysis of selected variables as related to non-motorized travel. The model specification is then presented. Finally, the results are presented and discussed, followed by conclusions and recommendations for future studies.

\section{Methodology}

\subsection{Data}

The first set of data used consisted of the 1990 and 1995 National Person Travel Survey (NPTS), which was a one-day travel survey conducted by the Research Triangle Institute. The 1990 NPTS was conducted between March 1990 and March 1991 with 21,869 households and yielded a response rate of 84 percent. The 1995 NPTS was a telephone survey conducted between May 1995 and July 1996 that collected travel information from more than 42,000 households. The second set of data used included the National Household Travel Survey (NHTS) from 2001 and 2009. The 2001 NHTS was a one-day travel survey that was collected via a telephone survey by Westat and Morpace from March 2001 to May 2002 and collected travel information from 69,817 households. The 2009 NHTS collected travel information from more than 150,000 households. Both the 2001 and 2009 NHTS included travel information from household members aged $0-4$, which was not done in the previous surveys. For consistency throughout the analysis, only the travel information that was common from all data sets was used in this study. Further, the study used travel information from households residing within the metropolitan statistics areas (MSAs). The unit of analysis in this study was a household since it is believed that most decisions are made at a household level [15]. Therefore, the final sample sizes used in this study were 12,494, $29,585,50,682$, and 109,321 for 1990, 1995, 2001, and
2009, respectively. The details of each of these datasets are well documented on the NHTS website [16].

\subsection{Descriptive Analysis}

Table 1 shows the changes in travel and selected socioeconomic variables known to influence travel from 1990 to 2009. In all analysis years, the percentage of walk trips was higher than the percentage of bicycle trips. This may be attributed to the fact that everyone becomes a pedestrian at some point throughout the day, but the same cannot be said about becoming a cyclist. The higher walk trips may also be attributed to increased walks to gain transit access [9]. The percentage of motorized trips showed a marginal decrease, while non-motorized trips increased marginally from 1990 to 2009 . The number of workers per household was lower in 2009 , but the number of vehicles per worker was higher in this same year. This may be explained by the economic recession that was ongoing during data collection, which affected the labor market. The household size, average trip length, and average daily household trips decreased slightly from 2001 to 2009 .

\subsection{Distribution of Non-Motorized Trips by Age and Income Groups}

Non-motorized travel involves exertion of physical energy; therefore, it is expected that the age of the individual is likely to influence his or her decision to use nonmotorized modes. Likewise, income may indicate the ability of a family to own, operate, and maintain a vehicle. Therefore, non-motorized trips were cross-tabulated with age and income groups, and the frequencies of trips made by each age and income group are shown in Figure 1.

In general, all else being equal, there was an opposite change in the non-motorized travel pattern for persons

Table 1. Changes in trip and selected demographic characteristics.

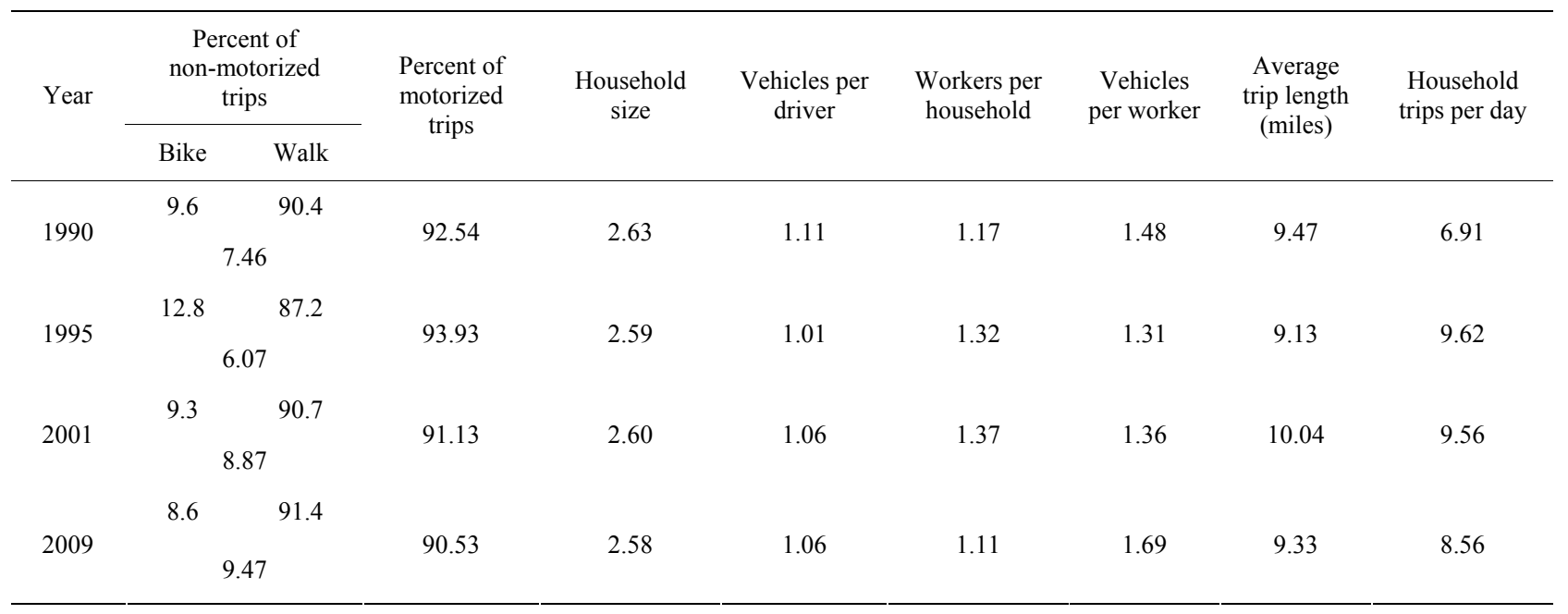




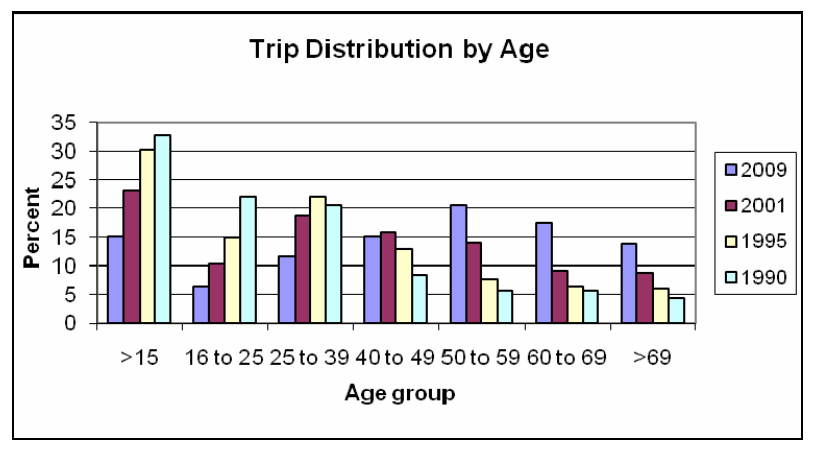

(a)

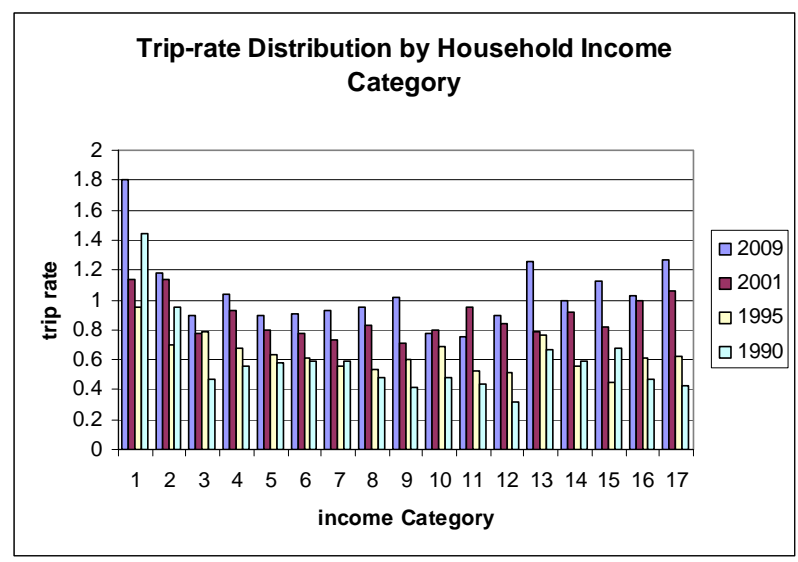

(b)

Figure 1. Non-motorized household trip rate by age (a) and income (b). Note: $1 \leq \$ 5000,2=\$ 5000-\$ 9999,3=\$ 10,000$ $\$ 14,999,4=\$ 15,000-\$ 19,999,5=\$ 20,000-\$ 24,999,6=$ $\$ 25,000-\$ 29,999,7=\$ 30,000-\$ 34,999,8=\$ 35,000-$ $\$ 39,999,9=\$ 40,000-\$ 44,999,10=\$ 45,000-\$ 49,999,11=$ $\$ 50,000-\$ 54,999,12=\$ 55,000-\$ 59,999,13=\$ 60,000-$ $\$ 64,999,14=\$ 65,000-\$ 69,999,15=\$ 70,000-\$ 74,999,16=$ $\$ 75,000$ - \$79,999, $17 \geq \$ 80,000$.

aged 39 or less and persons aged 40 or more. Specifically, non-motorized trips made by the younger group generally decreased over time, while non-motorized trips of the older group increased. This may be explained in part by the increased reliance on using private automobiles, rather than walking and bicycling, for making school trips, as reported in Ulfarsson and Shankar [17]. Persons aged 15 or less made more non-motorized trips than any other age group in 1990, 1995, and 2001, but this trend changed in 2009 , when persons aged 50 to 59 outpaced the $>15$ group by more than 5 percent. Consistent with other studies, low-income households made more nonmotorized trips compared to other income groups. However, the high-income households showed a monotonic increase in making non-motorized trips over time.

\subsection{Distribution of Non-Motorized Trips by Lifecycle}

Lifecycle defines the household composition and the extent of responsibilities a given household encounters. In general, it is expected that households with children make more trips than their counterparts. Figure 2 shows the distribution of non-motorized trips for each lifecycle category, as defined in Table 2. Households with two or more adults and children aged 6 to 15 had the highest percentage of non-motorized trips in 1990 but showed a decreasing trend over time. This may be explained by the relative independence of children aged 6 to 15 and thus the likelihood of them bicycling or walking to school or to playgrounds and/or parks near their homes [2]. It is apparent from Figure 2 that single-parent households made relatively fewer non-motorized trips than dualparent households. All else being equal, households with retired persons showed a monotonic increase in nonmotorized travel. Considering the increase in the aging population, this may indicate the need for bicycling and walking facilities for communities with higher populations of retired persons.

\subsection{Model Specification}

Several variables contained within the four cross-sectional datasets are known to influence travel behavior. Thus, an analysis was performed to identify which variables have a high influence on non-motorized and total travel, thus specifying a simple but robust model. After performing an analysis of variance and correlation ratio,

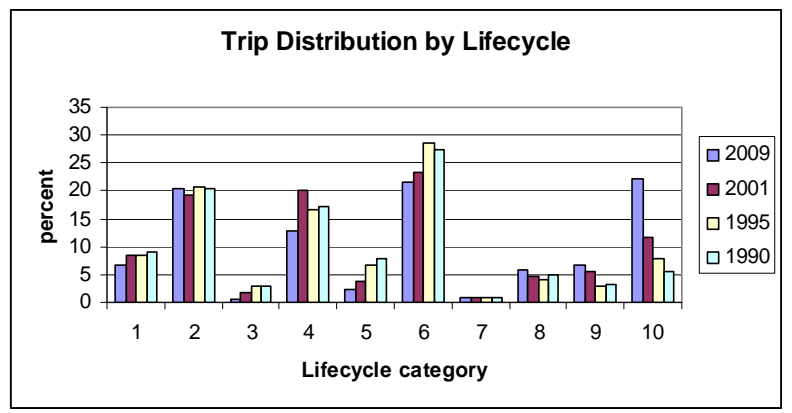

(a)

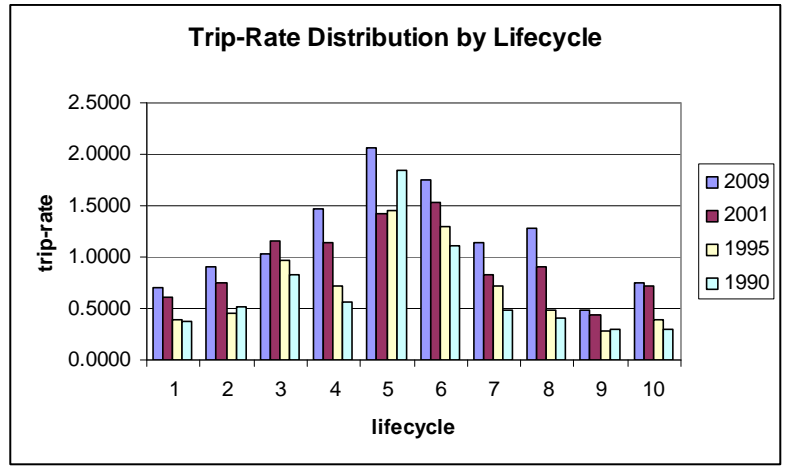

(b)

Figure 2. Non-Motorized trip distribution by household lifecycle. 
Table 2. Description of lifecycle codes.

\begin{tabular}{cc}
\hline Lifecycle Code & Code Description \\
\hline 1 & 1 adult, no children \\
2 & 2 + adults, no children \\
3 & 1 adult, youngest child 0 - 5 \\
4 & 2 + adults, youngest child 0 - 5 \\
5 & 1 adult, youngest child $6-15$ \\
6 & $2+$ adults, youngest child $6-15$ \\
7 & 1 adult, youngest child $16-21$ \\
8 & $2+$ adults, youngest child $16-21$ \\
9 & 1 adult, retired, no children \\
10 & $2+$ adults, retired, no children \\
\hline
\end{tabular}

the lifecycle of the household (lif_cyc), household size (hhsize), household income (income), number of workers (nworkers), number of licensed persons in a household (ndrivers), and number of vehicles (nvehicles) available for use by the household were specified in the final model. Though there were ten lifecycle categories, as previously defined in Table 2, only six categories were specified in the model since the other categories were statistically insignificant. Further analysis indicated that the model with log transformed household size (loghhsize) yielded a superior explanatory power than other specifications; thus, only the results for this specification are presented here. The formulated trip generation models took the following form:

$$
y_{i t}=\alpha_{t}+\sum_{k=1}^{K} x_{i t k} \beta_{t k}+\varepsilon_{i t}
$$

where

$i$ indexes household observations in period $t$,

$k$ indexes the household characteristics,

$y_{i t}$ is the number of trips made by household $i$ in pe$\operatorname{riod} t$,

$x_{i t k}$ is the $k^{\text {th }}$ household characteristic of household $i$ in period $t$,

$\alpha_{t}$ is the constant term for period $t$,

$\beta_{t k}$ is the $k^{\text {th }}$ coefficient of the $k^{t h}$ explanatory variable in period $t$, and

$\varepsilon_{i t}$ is the random term for household $i$ in period $t$.

The least squares estimator of the vector of model parameters for each period/cross section $t$ is given by

$$
\beta_{t}=\left(X_{t}^{T} X_{t}\right)^{-1}\left(X_{t}^{T} Y_{t}\right), t(\text { years })=1,2,3,4
$$

\section{Results and Discussion}

\subsection{Model Estimation Output}

The best-fit model for non-motorized travel was identified using the 1990 cross-sectional dataset as the base year. Similarly, for total travel, a less complex model with high explanatory power was estimated using the 1990 dataset. Thereafter, the same specification was estimated using Stata 9.0 for each of the other three crosssectional datasets. The model estimation results are presented in Table 3. Table 3 clearly shows that the demand for non-motorized and total travel increased with the increase in household size and the number of workers in a household, as indicated by the positive sign of their coefficients. This finding is consistent in all analyzed years. Similar findings have been reported in other studies $[1,2]$. With respect to household lifecycle, singleadult households with either children aged 6 - 15 or no children made more non-motorized trips than their twoadult household counterparts. In fact, single-person households made more non-motorized trips than all other household categories. Households with younger children aged 0 - 5 relied on other modes of transportation than bicycling and walking, as indicated by the negative sign of their coefficient. In 1990 and 1995, demand for nonmotorized travel declined with the increase in household income, as shown previously in Figure 1, and this is reflected by the negative sign of the income coefficient shown in Table 3. As shown in Figure 1, in recent years, demand for non-motorized travel has gotten higher for less affluent and affluent households but lower for medium-income households. This is further reflected by the change in sign and increase in magnitude for the income coefficient. For all analysis years, with the exception of 2009, total travel demand increased with the increase in household income, and this trend increased over time, as reflected by the increase in the magnitude of its coefficient.

As shown in Table 3, the increase in auto ownership impacted the demand for non-motorized travel negatively. The associated negative sign of the coefficient suggests that households with a higher number of vehicles have a lower propensity to take walking or bicycling trips. The increase in the number of vehicles per driver, as shown in Table 1, reduced the demand for non-motorized travel, which is further indicated by the change in sign of the coefficient for the number of licensed persons in a household. In contrast, the number of drivers affected the total travel demand positively, but the magnitude of its effect diminished over time, as reflected by a decrease in the magnitude of the coefficient for the number of drivers. The exogenous variables specified in the non-motorized demand model yielded more explanatory power in 1990 and less in 2001.

However, for total demand, the specified model yielded more explanatory power in 2001 and less in 1995. It is worth noting that the low explanatory power exhibited by the non-motorized model is consistent with what was encountered in the literature, indicating that the variables 
Table 3. Model parameter estimates for 1990, 1995, 2001, and 2009.

\begin{tabular}{|c|c|c|c|c|c|c|c|c|}
\hline \multirow{3}{*}{ Variable } & \multicolumn{4}{|c|}{1990} & \multicolumn{4}{|c|}{1995} \\
\hline & \multicolumn{2}{|c|}{ Non-Motorized } & \multicolumn{2}{|c|}{ Total Trips } & \multicolumn{2}{|c|}{ Non-Motorized } & \multicolumn{2}{|c|}{ Total Trips } \\
\hline & Coefficient & T-Ratio & Coefficient & T-Ratio & Coefficient & T-Ratio & Coefficient & T-Ratio \\
\hline lif_cyc1 & 0.4831 & 8.03 & & & 0.4404 & 10.58 & & \\
\hline lif_cyc2 & 0.1932 & 4.08 & & & 0.0376 & 1.12 & & \\
\hline lif_cyc3 & -0.2914 & -2.48 & & & -0.7393 & -8.43 & & \\
\hline lif_cyc4 & -0.446 & -6.93 & & & -0.724 & -15.19 & & \\
\hline lif_cyc5 & 0.8931 & 9 & & & 0.0243 & 0.35 & & \\
\hline lif_cyc6 & 0.1891 & 2.86 & & & 0.0356 & 0.77 & & \\
\hline loghhsize & 1.0684 & 18.59 & 3.5375 & 35.64 & 1.5363 & 32.67 & 6.6539 & 73.36 \\
\hline nworkers & 0.0408 & 1.63 & 1.1784 & 16.6 & 0.0265 & 1.55 & 0.3813 & 6.93 \\
\hline nvehicles & -0.4275 & -21.29 & & & -0.2998 & -20.4 & & \\
\hline income & -0.0218 & -5.51 & 0.0192 & 1.72 & -0.0006 & -0.23 & 0.0985 & 10.93 \\
\hline ndrivers & 0.0861 & 3.03 & 1.3754 & 17.82 & -0.3626 & -15.05 & 0.6599 & 9.87 \\
\hline constant & 0.3234 & 6.03 & 0.3829 & 3.29 & 0.556 & 14.96 & 1.7193 & 17.46 \\
\hline R-squared & 0.0 & & 0.31 & & 0.09 & & 0.3083 & \\
\hline F-Value & 1 & & 14 & & 26 & & 32 & \\
\hline $\mathrm{N}$ & \multicolumn{4}{|c|}{12,494} & \multicolumn{4}{|c|}{29,585} \\
\hline \multirow{4}{*}{ Variable } & \multicolumn{4}{|c|}{2001} & \multicolumn{4}{|c|}{2009} \\
\hline & \multicolumn{2}{|c|}{ Non-Motorized } & \multicolumn{2}{|c|}{ Total Trips } & \multicolumn{2}{|c|}{ Non-Motorized } & \multicolumn{2}{|c|}{ Total Trips } \\
\hline & Coefficient & T-Ratio & Coefficient & T-Ratio & Coefficient & T-Ratio & Coefficient & T-Ratio \\
\hline & 0.4269 & 12.87 & & & 0.4123 & 16.3 & & \\
\hline lif_cyc2 & -0.0123 & -0.46 & & & -0.018 & -0.91 & & \\
\hline lif_cyc3 & -0.6607 & -9.74 & & & -0.9024 & -14.51 & & \\
\hline lif_cyc4 & -0.5979 & -16.07 & & & -0.4767 & -15.94 & & \\
\hline lif_cyc5 & -0.1075 & -1.96 & & & 0.4086 & 9.63 & & \\
\hline lif_cyc6 & -0.026 & -0.73 & & & 0.0158 & 0.58 & & \\
\hline loghhsize & 1.4553 & 39.89 & 7.3460 & 104.2 & 1.4432 & 51.02 & 5.2693 & 116.8 \\
\hline nworkers & 0.0338 & 2.49 & 0.0152 & 0.38 & 0.1089 & 10.45 & 1.1266 & 49.68 \\
\hline nvehicles & -0.255 & -24.96 & & & -0.4177 & -54.36 & & \\
\hline income & 0.0119 & 6.50 & 0.1448 & 23.75 & 0.0165 & 11.79 & 0.1066 & 31.08 \\
\hline ndrivers & -0.2807 & -15.12 & 0.4269 & 8.32 & -0.1043 & -7.29 & 0.2431 & 7.80 \\
\hline constant & 0.5829 & 20.97 & 1.3409 & 17.90 & 0.6008 & 27.99 & 1.4277 & 31.04 \\
\hline R-squared & 0.0 & & 0.34 & & 0.08 & & 0.3 & \\
\hline F-Value & 3 & & 66 & & 92 & & 13 & \\
\hline $\mathrm{N}$ & & & & & & 109 & & \\
\hline
\end{tabular}


specified in the model provided little explanation of the variation in non-motorized household trips. This reflects the difficulty in explaining non-motorized travel with conventional variables.

\subsection{Temporal Stability of Model Coefficients}

As noted in the introduction, the collection and use of cross-sectional models relies on the assumption that the population is at an equilibrium point with respect to travel behavior and that the estimated model parameters can be applied to a future context. This assumption implies that the estimated model parameters are temporally invariant. To test temporal stability of estimated model parameters for both non-motorized and total travel, the 1990 cross-sectional model was tested against the more recent datasets; the same was done with the 1995 and 2001 models. Testing was done using the student $t$-test defined below:

$$
t=\frac{\beta_{T+1}-\beta_{T}}{\sqrt{\operatorname{var}\left(\beta_{T+1}\right)+\operatorname{var}\left(\beta_{T}\right)}}
$$

where

$\beta_{T+1}$ and $\beta_{T}$ are the coefficients for a given variable from the design year model $(T+1)$ and base year model $(T)$, respectively, and $\operatorname{var}\left(\beta_{T+1}\right)$ and $\operatorname{var}\left(\beta_{T}\right)$ are their respective variances.

The resulting $t$-statistics are shown in Table 4 . In the 1990 model, the only coefficient that was statistically stable at a 5 percent significance level was a dummy variable for single-person household with no children; this coefficient was invariant across all analysis years. In the 1995 model, the coefficients for lifecycles 1 through 3 and 6 , logarithm of household size, and the constant term were temporally stable, whereas the other variables were either stable in 2001 or 2009 or not stable in 2001 and 2009. In the short-term temporal stability check from 2001 to 2009, not all of the model parameters were stable. Table 4 shows that six of the 2001 model parameters were stable at a 5 percent significance level. For total travel demand, only the constant term showed stability from 2001 to 2009.

The difference in the vector of model parameter estimates for the estimation and application periods is

Table 4. T-statistics.

\begin{tabular}{|c|c|c|c|c|c|c|}
\hline \multirow{2}{*}{$\begin{array}{c}\text { From } \\
\text { To }\end{array}$} & \multicolumn{3}{|c|}{1990} & \multicolumn{2}{|c|}{1995} & \multirow{2}{*}{$\begin{array}{l}2001 \\
2009\end{array}$} \\
\hline & 1995 & 2001 & 2009 & 2001 & 2009 & \\
\hline \multicolumn{7}{|c|}{ For Non-Motorized Trips } \\
\hline lif_cyc1 & -0.58 & -0.82 & -1.08 & -0.25 & -0.58 & -0.35 \\
\hline lif_cyc2 & -2.68 & -3.78 & -4.12 & -1.16 & -1.43 & -0.17 \\
\hline lif_cyc3 & -3.06 & -2.72 & -4.60 & 0.71 & -1.52 & -2.63 \\
\hline lif_cyc4 & -3.47 & -2.04 & -0.43 & 2.09 & 4.39 & 2.54 \\
\hline lif_cyc5 & -7.15 & -8.82 & -4.49 & -1.48 & 4.69 & 7.44 \\
\hline lif_cyc6 & -1.90 & -2.86 & -2.42 & -1.05 & -0.37 & 0.93 \\
\hline loghhsize & 6.30 & 5.68 & 5.85 & -1.36 & -1.70 & -0.26 \\
\hline nworkers & -0.47 & -0.25 & 2.52 & 0.33 & 4.13 & 4.40 \\
\hline nvehicles & 5.13 & 7.66 & 0.46 & 2.50 & -7.12 & -12.72 \\
\hline income & 4.51 & 7.74 & 9.13 & 4.00 & 5.88 & 1.95 \\
\hline ndrivers & -12.05 & -10.81 & -5.99 & 2.69 & 9.22 & 7.52 \\
\hline constant & 3.56 & 4.30 & 4.80 & 0.58 & 1.04 & 0.51 \\
\hline \multicolumn{7}{|c|}{ For Total Trips } \\
\hline loghhsize & 23.18 & 31.28 & 15.88 & 6.02 & -13.67 & -24.81 \\
\hline nworkers & -27.81 & -32.93 & -23.68 & -67.01 & -59.12 & 24.24 \\
\hline income & -34.51 & -34.12 & -34.55 & -71.60 & -72.13 & -5.45 \\
\hline ndrivers & -24.04 & -27.84 & -31.67 & -59.75 & -66.84 & -3.06 \\
\hline constant & -13.00 & -17.67 & -19.29 & -45.16 & -51.39 & 0.99 \\
\hline$\alpha=0.05$ & \multicolumn{6}{|c|}{ Critical value is \pm 1.96} \\
\hline
\end{tabular}


to as the transfer bias. Larger differences signify the magnitude of changes in travel behavior and their respective explanatory variables from the estimation to application time period. In general, the $t$-statistics yielded by the total travel models were larger compared to those yielded by the non-motorized models.

\subsection{Prediction of Non-Motorized and Total Travel in the Estimation Data Using Models Estimated on 1990, 1995, 2001, and 2009 Data}

Usually, little is known to a modeler about future context; hence, the modeler selects the best model based on a model's capability to replicate travel in the estimation context. Thus, in this study, the estimated models were applied to predict non-motorized and total travel, each in its respective estimation dataset. The Mean Absolute Error (MAE) and Percent Error (PE) were used to assess the models' capability in forecasting travel in the estimation data. The MAE measure has been used by other studies $[18,19]$. MAE is calculated as:

$$
M A E=\frac{\sum_{i=1}^{N}\left|y_{i}-\hat{y}_{i}\right| w_{i}}{\sum_{i=1}^{N} w_{i}}
$$

where

$y_{i}$ is the observed number of non-motorized trips produced by household $i$,

$\hat{y}_{i}$ is the predicted number of non-motorized trips produced by household $i$,

$w_{i}$ is the weighting factor, and

$N$ is the sample size, all in a given year.

The prediction results are presented in Table 5, which shows that the error measure, MAE, increased in magnitude over time for non-motorized travel. For total travel, the MAE value was lower in 1990 and higher in 1995.

Further analysis was done to identify in which part of the US the models were unable to predict non-motorized travel demand. The results, which are presented in Table 6, consistently showed that all of the models studied over-predicted non-motorized travel in the South Central

Table 5. Outputs for prediction on estimation data.

\begin{tabular}{|c|c|c|c|c|c|}
\hline Model & Trip Type & Constant & Coefficient & R-Squared & MAE \\
\hline \multirow{2}{*}{1990} & Non-Motorized & $2.43 \mathrm{E}-09$ & 1 & 0.0920 & 0.911 \\
\hline & Total & $5.76 \mathrm{E}-09$ & 1 & 0.3102 & 3.747 \\
\hline \multirow{2}{*}{1995} & Non-Motorized & $-1.06 \mathrm{E}-09$ & 1 & 0.0906 & 0.955 \\
\hline & Total & $1.85 \mathrm{E}-08$ & 1 & 0.3083 & 4.767 \\
\hline \multirow{2}{*}{2001} & Non-Motorized & $-1.79 \mathrm{E}-09$ & 1 & 0.0749 & 1.214 \\
\hline & Total & $-1.01 \mathrm{E}-08$ & 1 & 0.3448 & 4.523 \\
\hline \multirow{2}{*}{2009} & Non-Motorized & $1.32 \mathrm{E}-09$ & 1 & 0.0851 & 1.396 \\
\hline & Total & $-2.88 E-08$ & 1 & 0.3344 & 3.912 \\
\hline
\end{tabular}

Table 6. Observed and predicted total non-motorized trips by division for each analysis year.

\begin{tabular}{|c|c|c|c|c|c|c|c|c|c|c|}
\hline & Model & $\begin{array}{c}\text { New } \\
\text { England }\end{array}$ & $\begin{array}{l}\text { Middle } \\
\text { Atlantic }\end{array}$ & $\begin{array}{c}\text { East } \\
\text { North } \\
\text { Central }\end{array}$ & $\begin{array}{c}\text { West } \\
\text { North } \\
\text { Central }\end{array}$ & $\begin{array}{c}\text { South } \\
\text { Atlantic }\end{array}$ & $\begin{array}{c}\text { East } \\
\text { South } \\
\text { Central }\end{array}$ & $\begin{array}{c}\text { West } \\
\text { South } \\
\text { Central }\end{array}$ & Mountain & Pacific \\
\hline \multirow{3}{*}{1990} & Observed & 738 & 2241 & 1235 & 291 & 787 & 163 & 382 & 212 & 1118 \\
\hline & Predicted & 831 & 1,602 & 1,426 & 339 & 976 & 305 & 658 & 277 & 978 \\
\hline & $\mathrm{PE}$ & 12.6 & -28.5 & 15.5 & 16.5 & 24 & 87.3 & 72.2 & 30.7 & -12.5 \\
\hline \multirow[t]{2}{*}{1995} & Predicted & 4.064 & 6.775 & 1,480 & 426 & 1.644 & 314 & 2.564 & 375 & 1.667 \\
\hline & $\mathrm{PE}$ & 22.6 & -15.4 & 6.6 & 9.4 & 37.4 & 85.7 & 112.3 & -21 & -7.4 \\
\hline \multirow{3}{*}{2001} & Observed & 914 & 13,862 & 12,681 & 1404 & 5.685 & 523 & 1736 & 1110 & 4339 \\
\hline & Predicted & 901 & 12,302 & 13,256 & 1,840 & 5.903 & 1.060 & 3.298 & 1040 & 4.257 \\
\hline & $\mathrm{PE}$ & -1.4 & -11.3 & 4.5 & 31.1 & 3.8 & 102.8 & 90 & -6.3 & -1.9 \\
\hline \multirow[t]{2}{*}{2009} & Predicted & 1444 & 13229 & 4414 & 4615 & 33130 & 1747 & 16829 & 6858 & 18551 \\
\hline & PE & -6.7 & 0.9 & 23 & 40.6 & 26.8 & 81.8 & 51.5 & 8.5 & -11.5 \\
\hline
\end{tabular}


Divisions, which include states like Texas and Tennessee. The models predicted non-motorized travel well for the Pacific Division, which includes California. The lackluster performance of all the presented models in predicting travel in the East South Central Division may be attributed to low sample representation compared to other divisions. The differences in the models' ability to predict travel in the different divisions implies differences in travel behavior exhibited by households in the respective divisions. Divisions with lower PE values may have the advantage of using the national travel survey datasets for understanding non-motorized travel patterns and behavior in their regions and updating their travel demand models. This may be further investigated by formulating models for each division.

\subsection{Prediction of Non-Motorized and Total Travel in 2009 Using Models Estimated on 1990, 1995, and 2001 Data}

The models estimated on the 1990, 1995, and 2001 data were used to predict non-motorized and total travel in the application contexts. Along with the MAE value described previously, the Transfer Index (TI) was used to measure how well the estimation context model predicted the observed trips in the application context relative to the application context model. Mathematically, $T I$ is expressed as [20]:

$$
T I=\frac{R_{\text {transferred }}^{2}}{R_{\text {local }}^{2}}
$$

The results are presented in Table 7, which illustrates that the magnitude of the resulting error measure from the application of the 1990 model to predict travel de- mand in the three periods increased with time. The 1990 model better explained non-motorized travel at the household level for 1995 than for 2001, as indicated by the large value of the transfer index. The 1995 model better explained trip variability for 2009 than 2001, even though the reverse would be expected since one would expect fewer changes in land use, household structure, and travel patterns in 2001 than in 2009. The 2001 model explained travel relatively well for the 2009 local model. With respect to total travel, all the transferred models explained trip variation less than the local models, as reflected by their respective lower $T I$ values. From Table 7, it is evident that the total travel models transferred better in time than the non-motorized models. It is worth noting that the MAE value yielded by the 2009 model's application in estimation data was large compared to the transferred models. This may be due in part to changes in variables explaining non-motorized travel that are not specified in the model.

Further, a comparison of the models' ability to predict observed trips in 2009 by household size and household income was undertaken, and the results are depicted in Figures 3 and 4, respectively. This was done to investigate whether modelers should model by market segmentation rather than the unified approach employed in this study. As observed in Figure 3, the relationship between non-motorized and total trip rate and household size for both 2009 observed trips and predicted trips by eachmodel was non-linear, with trip rate increasing monotonically with increased household size. This was expected since the proportion of children in a household, who make fewer trips on average than adults, increased as household size grew. In addition, the trip rate increase decreased with the increase in household size, which was

Table 7. Outputs for prediction of non-motorized travel in future contexts.

\begin{tabular}{|c|c|c|c|c|c|c|c|}
\hline Model & Application & Trip Type & Constant & Coefficient & Transfer $R^{2}$ & MAE & $T I$ \\
\hline \multirow{6}{*}{1990} & \multirow{2}{*}{1995} & Non-Motorized & 0.1107 & 0.9247 & 0.0741 & 0.946 & 0.87 \\
\hline & & Total & 1.0893 & 1.1582 & 0.2833 & 4.881 & 0.92 \\
\hline & \multirow{2}{*}{2001} & Non-Motorized & 0.5223 & 0.7815 & 0.0555 & 1.106 & 0.65 \\
\hline & & Total & 0.7938 & 1.1551 & 0.3042 & 4.655 & 0.88 \\
\hline & \multirow{2}{*}{2009} & Non-Motorized & 0.6447 & 0.9746 & 0.0684 & 1.237 & 0.80 \\
\hline & & Total & 0.7369 & 1.0671 & 0.3213 & 3.910 & 0.96 \\
\hline \multirow{4}{*}{1995} & \multirow{2}{*}{2001} & Non-Motorized & 0.3794 & 0.8882 & 0.0703 & 1.102 & 0.83 \\
\hline & & Total & -0.4849 & 1.0208 & 0.3424 & 4.551 & 0.99 \\
\hline & \multirow{2}{*}{2009} & Non-Motorized & 0.4776 & 1.0487 & 0.0733 & 1.238 & 0.86 \\
\hline & & Total & -0.1068 & 0.8759 & 0.3253 & 4.203 & 0.97 \\
\hline \multirow{2}{*}{2001} & \multirow{2}{*}{2009} & Non-Motorized & 0.0036 & 1.1965 & 0.0800 & 1.331 & 0.94 \\
\hline & & Total & 0.3501 & 0.8385 & 0.3182 & 4.209 & 0.95 \\
\hline
\end{tabular}




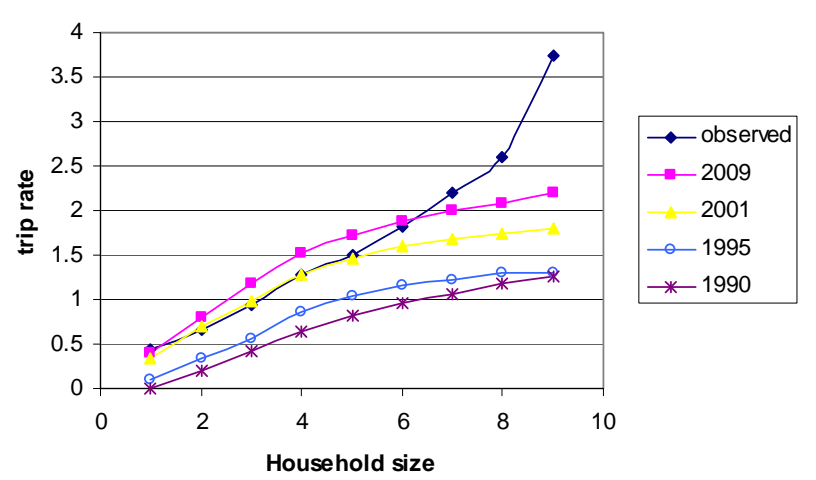

(a)

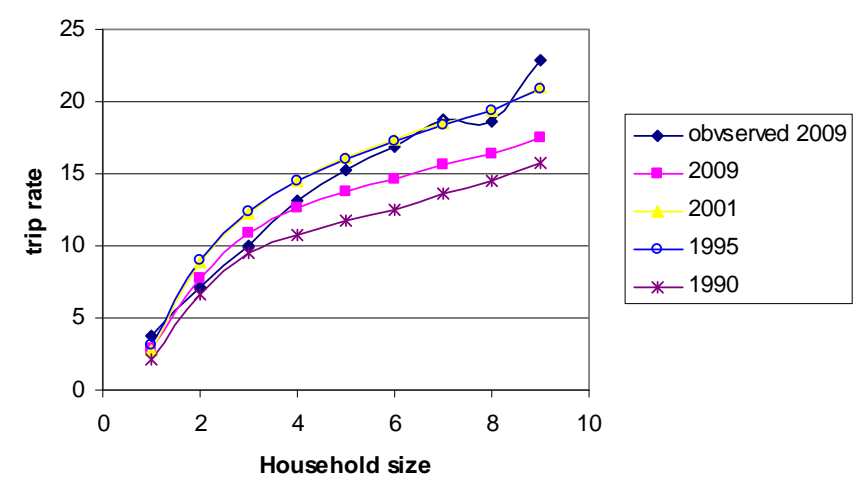

(b)

Figure 3. Comparative picture of observed household trip rate in 2009 versus predicted trip rate, by household size, using 2009, 2001, 1995, and 1990 models.

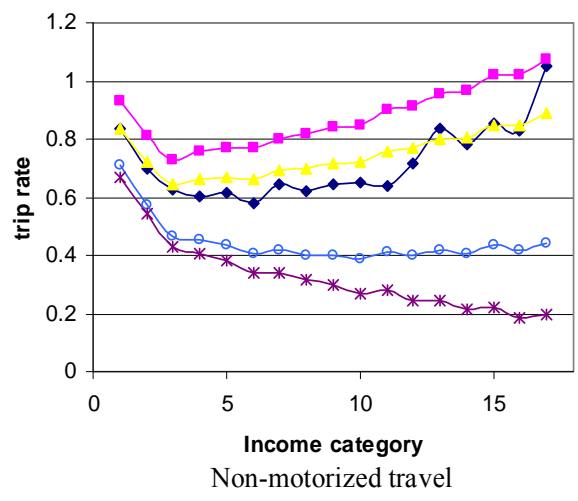

(a)
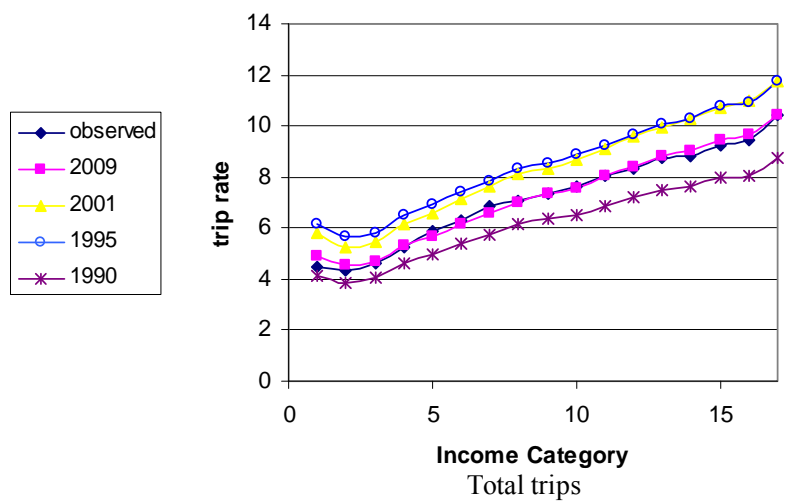

(b)

Figure 4. Comparative picture of observed household trip rate in 2009 versus predicted trip rate, by household income, using 2009, 2001, 1995, and 1990 models.

also expected since some trip purposes, such as grocery shopping, can be done by one household member for the whole family.

With respect to non-motorized travel, the rate of increase showed three household groups. The first group, which had the larger rate, was composed of households with four or fewer persons. The second group, with a medium trip rate increase, included households with five or six persons, and the third group, which has the lowest trip rate increase, was composed of households with seven or more persons. Of all the models, the 2001 model better predicted trips in 2009 for households with five or fewer people than any other model. For total travel, all else being equal, the 1995 model better predicted travel in 2009 for a single-person household. The 1990 model better predicted travel for two- and three-person households, the 2009 model better predicted travel for fourperson households, and the 1995 and 2001 models better predicted travel for households with five or more persons.

With respect to income, non-motorized trip rates were higher for low-income and high-income households but low for medium-income households. The low performance of the 1990 and 1995 models in predicting travel in 2009 for households that were more affluent can be explained by the low likelihood of this group to make non-motorized trips in those years. This trend was not the same for this group in 2009, when members made more non-motorized trips. As observed in Figure 4, with regard to income, the 2001 model predicted non-motorized trips better than any of the other studied models. In contrast, for total travel, all models exhibited a similar trend and showed three distinct groups. As expected, the estimated 2009 model best predicted the observed travel in 2009.

\section{Summary and Conclusions}

This study investigated changes in non-motorized and total travel and the characteristics of the traveling public that are relevant to non-motorized modeling in 1990 , 1995, 2001, and 2009. The study also investigated the temporal transferability of linear-regression trip generation models for non-motorized and total travel under such changes. The relevant changes in non-motorized and total travel and urban characteristics included the following: 
- In general, high-income households made few nonmotorized trips in 1990 and 1995. However, the trend changed in 2001 and 2009 for this group, with an increase in non-motorized trips. Persons aged 50 and over showed an increased demand for non-motorized travel, whereas children aged 0 - 15 showed a decreasing preference for non-motorized travel over time.

- With the exception of Lifecycle 2, 3, and 5, all the household structures showed an increasing demand in non-motorized travel over time.

- Change in the composition of households was reflected in an increase in the number of workers per household, an increase in the number of vehicles per worker, and a decrease in the household size.

- With the exception of 2009, there was an increase in the average total number of trips made per household, notwithstanding the decline in average household size. This suggests that changes in the socioeconomic structure of households and lifestyle changes were influential factors in the increase in trips.

The empirical investigation on the temporal transferability of non-motorized and total trip generation models yielded the following findings:

- The increase in vehicle ownership impacted the demand for non-motorized travel negatively. However, further analysis is required to identify the level of inter-relationship between the number of vehicles owned and the number of non-motorized trips made for a given household.

- For non-motorized travel, only the coefficient for single-adult households with no children was stable across all of the analysis years. For both non-motorized and total travel, most model parameter estimates were stable short term but not long term.

- With respect to the models' transferability to 2009 , the 2001 model predicted travel better than the 1990 and 1995 models. Further, the models' ability to predict travel in future contexts decreased with increasing time between estimation and application contexts. This indicates the inability of a model to capture large changes in urban structure and travel behavior.

- In general, in all analysis years, the total travel models transferred better than non-motorized models.

In general, despite not finding universal stability in model parameter estimates, the models were marginally able to replicate travel in 2009 relative to the locally estimated 2009 model. This study gives a general picture of the temporal transferability of non-motorized travel compared to total travel using the available national datasets. More research is required, particularly at the regional level, to understand a region's specific changes in land use and travel behavior and their influence on non-motorized travel. Further, well-specified models incorporating land use variables may be appropriate where the data are available to improve models' ability to explain variations of non-motorized travel.

\section{REFERENCES}

[1] M. R. Baltes, "Factors Influencing Nondiscretionary Work Trips by Bicycle Determined from 1990 US Census Metropolitan Statistical Area Data, Transportation Research Record 1538," Transportation Research Board, Washington DC, 1996, pp. 96-101.

[2] C. R. Bhat, J. Y. Guo and R. Sardesai, "Non-Motorized Travel in the San Francisco Bay Area," University of Texas, Austin, 2005.

[3] Urban Transportation Caucus, "Urban Transportation Report Card, San Francisco Bike Coalition, Cascade Bicycle Club, and Chicago Land Bicycle Federation Transportation Alternatives, 2007.

[4] Urban Mobility Report, Texas Transportation Institute, The Texas A \& M University System, Austin, 2004.

[5] D. Shrank and T. Lomax, 2009 Urban Mobility Report, Texas Transportation Institute, The Texas A \& M University System, Austin, 2009.

[6] M. Replogle, "Integrating Pedestrian and Bicycle Factors into Regional Transportation Planning Models: Summary of the State-Of-The-Art and Suggested Steps Forward," Urban Design, Telecommunication and Travel Forecasting Conference: Summary, Recommendations and Compendium of Papers, Travel Model Improvement Program, Williamsburg, 27-30 October, 1996, pp. 75-94.

[7] K. J. Crifton and K. J. Krizek, "The Utility of the NHTS in Understanding Bicycle and Pedestrian Travel," $\mathrm{Na}$ tional Household Travel Survey Conference: Understanding Our Nation's Travel, Washington DC, 1-2 November 2004.

[8] US Department of Transportation, Bureau of Transportation Statistics, Bicycle and Pedestrian Data Sources, Needs and Gaps, Washington DC, 2000.

[9] C. R. Emond, W. Tang and S. L. Handy, "Explaining Gender Difference in Bicycling Behavior," Transportation Research Board, Washington DC, 2009, pp. 16-25.

[10] R. Cervero and M. Duncan, "Walking, Bicycling, and Urban Landscapes: Evidence from the San Francisco Bay Area," American Journal of Public Health, Vol. 93, No. 9, 2003, pp. 1478-1483. doi:10.2105/AJPH.93.9.1478

[11] E. J. Kannel and K. W. Heathington, "Temporal Stability of Trip Generation Relations," Highway Research Record, Vol. 472, 1973, pp. 17-27.

[12] A. Cotrus, J. N. Prashker and Y. Shiftan, "Spatial and Temporal Transferability of Trip Generation Demand Models in Israel, Bureau of Transportation Statistics," Journal of Transportation and Statistics, Vol. 8 No. 1, 2003, pp. 37-56.

[13] Oak Ridge National Laboratory, "The 2001 National Household Travel Survey," Oak Ridge National Laboratory for the US Department of Transportation, 2004. http:/nhts.ornl.gov/publications.html

[14] J. L. Mwakalonge, "Econometric Modeling of Total Urban Travel Demand Using Data Collected in Single and 
Repeated Cross-Sectional Surveys," Ph.D. Dissertation, Department of Civil and Environmental Engineering, Tennessee Technological University, Cookeville, 2010.

[15] K. G. Goulias, R. M. Pendyala and R. Kitamura, "Practical Method for the Estimation of Trip Generation and Trip Chaining," Transportation Research Board, Washington DC, 1991, pp. 47-56.

[16] Oak Ridge National Laboratory, "The National Household Travel Survey," Oak Ridge National Laboratory for the US Department of Transportation, 2010. http:/nhts.ornl.gov/publications.html

[17] G. F. Ulfarsson and V. N. Shankar, "Children's Travel to School: Discrete Choice Modeling of Correlated Motorized and Non-Motorized Transportation Modes Using Covariance Heterogeneity," Environment and Planning B:
Planning and Design, Vol. 35, No. 2, 2008, pp. 195-206. doi:10.1068/b3360

[18] A. Hadayeghi, A. S. Shalaby, B. N. Persaud and C. Cheung, "Temporal Transferability and Updating of Zonal Level Accident Prediction Models," Accident Analysis \& Prevention, Vol. 38, No. 3, 2006, pp. 579-589. doi:10.1016/j.aap.2005.12.003

[19] D. A. Badoe, "An Investigation into the Long Range Transferability of Work-Trip Discrete Mode Choice Models," Ph.D. Dissertation, University of Toronto, Toronto, 1994.

[20] F. S. Koppelman and C. G. Wilmot, "Transferability Analysis of Disaggregate Choice Models," Transportation Research Board, Washington DC, 1982, pp. 18-24. 